\title{
Correlates of the difference in plasma carotenoid concentrations between men and women
}

\author{
Tatiana Allore ${ }^{1}$, Simone Lemieux ${ }^{1,2}$, Marie-Claude Vohl ${ }^{1,2}$, Patrick Couture ${ }^{1,3}$, Benoît Lamarche ${ }^{1,2}$ \\ and Charles Couillard ${ }^{1,2 *}$ \\ ${ }^{1}$ Institute of Nutrition and Functional Food, Université Laval, Québec, Canada G1V OA6 \\ ${ }^{2}$ School of Nutrition, Université Laval, Québec, Canada G1V OA6 \\ ${ }^{3}$ Lipid Research Center, CHU de Québec - CHUL, Québec, Canada G1V 4 G2 \\ (Submitted 22 December 2017 - Final revision received 27 August 2018 - Accepted 28 September 2018 - First published online 5 November 2018)
}

\section{Abstract}

Health professionals consider the evaluation of eating habits to be challenging, given the potential biases of dietary questionnaires based on self-reported data. Circulating carotenoid concentrations are reliable biomarkers of dietary carotenoid intake and could be useful in the validation of dietary assessment tools. However, there is a sex difference in circulating carotenoids, with women displaying higher concentrations compared with men independent of intake. The aim of the present study was to identify the correlates of plasma carotenoid concentrations among men ( $n$ 155) and women $(n$ 110) enrolled in six fully controlled dietary interventions with varying dietary carotenoid intakes. We looked at the associations of post-intervention fasting plasma carotenoid concentrations ( $\alpha$-carotene, $\beta$-carotene, $\beta$-cryptoxanthin, lutein, lycopene and zeaxanthin) with physical and metabolic characteristics. We found that increased body weight $(r-0 \cdot 47, P<0 \cdot 0001)$ and waist circumference $(r-0.46, P<0.0001)$ were associated with lower plasma total carotenoid concentrations, while elevated plasma LDLcholesterol $(r 0.49, P<0.0001)$ and HDL-cholesterol $(r 0.50, P<0.0001)$ concentrations were correlated with higher total carotenoids in plasma. Women had significantly higher plasma total carotenoid concentrations compared with men, despite significantly lower dietary carotenoid intake. Adjustment of circulating carotenoid concentrations for plasma HDL-cholesterol eliminated sex difference in plasma carotenoid concentrations. Our results suggest that physical characteristics as well as plasma lipids are associated with circulating carotenoid concentrations and that these variables should be taken into account when using plasma carotenoids as biomarkers for food intake in men and women.

Key words: Carotenoids: Fruits: Vegetables: Sex differences: Biomarkers

Compliance with nutritional guidelines is an important factor to consider when investigating the health effects associated with the consumption of a healthy, well-balanced diet. To that effect, the reliability and accuracy of dietary habits assessment are critical in establishing compliance, but this remains an enduring challenge for dietitians and health professionals. Indeed, several dietary assessment methods have been developed and used to measure nutritional habits, including food diaries, FFQ and 24-h recalls ${ }^{(1)}$. The attractiveness of these assessment tools resides in the easiness and affordability related to their administration. However, as these tools are based on self-reported data, their value has been challenged by some due to the perceived risk of biased data collection attributable, amongst others, to underand/or over-estimating the consumption of certain foods ${ }^{(2)}$.

In this regard, there is increasing interest in the use of nutritional biomarkers (measured in blood, urine or saliva), as they have been suggested to offer a more reliable and accurate assessment of dietary exposure and nutritional status ${ }^{(3)}$. For instance, urinary $\mathrm{N}$ is recognised as an excellent recovery biomarker of protein intake ${ }^{(4)}$. Doubly labelled water is the gold standard technique for measurement of energy metabolism ${ }^{(5)}$ and estimation of energy requirements ${ }^{(6)}$ but remains a technique that is costly and requires specific technical skills and facilities. On the other hand, circulating carotenoids are recognised as good correlates of dietary carotenoid intakes ${ }^{(7)}$. Furthermore, as fruits and vegetables (FAV) provide more than $90 \%$ of the daily carotenoid intake ${ }^{(8)}$, measuring plasma carotenoid concentrations has been suggested as a more precise evaluation of an individual's compliance with current nutritional recommendations, focusing on increased consumption of FAV for a better health than self-reported data ${ }^{(9-12)}$. In line with this observation, we recently reported that plasma lutein and $\beta$-cryptoxanthin are better biomarkers of the consumption of FAV compared with plasma $\alpha$-carotene, $\beta$-carotene or lycopene

Abbreviation: FAV, fruits and vegetables.

* Corresponding author: C. Couillard, email charles.couillard@fsaa.ulaval.ca 
concentrations that are more likely to be affected by the consumption of foods other than $\mathrm{FAV}^{(13)}$.

Besides dietary carotenoid intake, circulating carotenoid concentrations are also affected by age, physical activity, smoking and alcohol consumption ${ }^{(14-17)}$. In addition, obesity ${ }^{(18)}$ and low total LDL- and HDL-cholesterol concentrations ${ }^{(18,19)}$ have been associated with lower circulating carotenoid concentrations. A sex difference is also noted in circulating carotenoid concentrations in women displaying higher concentrations compared with men ${ }^{(15,17-20)}$. Therefore, the aim of the present study was to identify the correlates of plasma carotenoid concentrations among men and women and investigate whether variations in physical and metabolic parameters as well as dietary carotenoid intake contribute to the higher plasma carotenoid concentrations in women compared with men. We hypothesise that the difference noted in plasma carotenoid concentrations between men and women is explained at least in part by differences in adiposity and plasma lipoprotein-lipid profile.

\section{Methods}

\section{Subjects}

For the present analyses, we used data from a group of 155 men and 110 women who participated in a series of dietary interventions we previously conducted. The specific selection criteria of participants enrolled in each intervention have been previously published $^{(21-25)}$. Briefly, men and women had to be healthy and not under treatment for hypertension, CVD, type 2 diabetes or other endocrine disorders. Smoking, alcohol consumption ( $>1$ drink/d) and dietary supplement use were also considered reasons to exclude participants. Each participant gave their informed written consent to take part in the different interventions that were all approved by the Human Research Ethics Committee of Université Laval.

\section{Dietary interventions}

Data from a series of fully controlled isoenergetic dietary interventions conducted by our research group since 2006 were used for the present analyses. Complete detailed descriptions of Diet 1 (NCT00930137) ${ }^{(21)}$, Diet 2 (NCT01351012) $^{(22)}$, Diet 3 $\left(\right.$ NCT01293344) ${ }^{(23)}$, Diets 4 and 5 (registered at ClinicalTrials. gov as NCT00988650) ${ }^{(24)}$ and Diet 6 (NCT01163175) ${ }^{(25)}$ have been previously published ${ }^{(13)}$ and are provided as online Supplementary Table S1 in the present article. These dietary interventions covered a wide range of daily carotenoid intakes (from 13.6 to $51.3 \mathrm{mg} / \mathrm{d}$ ) almost exclusively coming from mixed FAV consumption. In brief, Diets $1(17.6$ (sD $2 \cdot 1) \mathrm{mg} / \mathrm{d}$ of carotenoids) and $6(37 \cdot 3(\mathrm{sD} 6 \cdot 1) \mathrm{mg} / \mathrm{d}$ of carotenoids) were four-week control diets low in trans-fatty acids (TFA) of ruminant origin from studies investigating the metabolic impact of TFA from dairy; Diet $2(25.5$ (sD 4.8$) \mathrm{mg} / \mathrm{d}$ of carotenoids) was part of a study looking at the metabolic impacts of different vegetable oils and consisted of a four-week, weight-maintaining diet of fixed macronutrient composition for protein $(15 \%$ of energy), carbohydrates (50\% of energy) and fats (35\% of energy), with a blend of maize and safflower oils (25:75), contributing to dietary fat intake (18\%); Diets 3 (28.6 (sD $5 \cdot 1) \mathrm{mg} / \mathrm{d}$ of carotenoids) and $5(31.0$ (SD 4.3$) \mathrm{mg} / \mathrm{d}$ of carotenoids) corresponded to five-week Mediterranean diets - that is, they contained key foods of the Mediterranean pyramid (e.g. olive oil, whole-grain products, FAV, legumes, nuts, cheese and yogurt, fish, poultry and red wine) ${ }^{(26)}$. Diet 4 (mean intake: $29 \cdot 4$ (SD 4.3 ) $\mathrm{mg} / \mathrm{d}$ of carotenoids) was a five-week control diet of a study assessing the impact of the Mediterranean diet and was designed to reflect average macro-nutrient intake in North American men ${ }^{(27)}$.

In all cases, subjects arrived at our Clinical Investigation Unit (CIU) on weekdays to have their body weight measured and consume their lunch meal (approximately 35\% of daily energy intake) under staff supervision. All foods and beverages were prepared and packaged at the CIU, and participants were provided with their evening meals and the next day's breakfast to take home, giving us the opportunity to control for energy, macro-nutrient and food intakes. Interventions were conducted under isoenergetic conditions to assure body weight maintenance, and a seven-d cyclic menu was used in all dietary interventions. Participants were instructed to consume only the foods provided, and compliance was found to be excellent ( $>95 \%$ in all cases). Dietary interventions were formulated using the Nutrition Data System software (version 4.03_31; Nutrition Coordinating Center). Participants were instructed to maintain their usual physical activity concentration throughout the experiments except for the threed that preceded blood sampling at the end of the feeding period, during which they were asked to refrain from intense physical exercise. Dietary carotenoid intake was calculated using the 2010 Canadian Nutrient File (http://webprod3.hc-sc.gc.ca/cnf-fce/index-eng. jsp), which was also used to obtain the energy, macronutrient and micronutrient contents of the different diets.

\section{Anthropometry}

Body weight, height as well as waist circumference of each participant were measured using standardised procedures ${ }^{(28)}$. BMI was calculated by dividing the body weight (kg) by the height (m) squared.

\section{Plasma measurements}

Lipid profile. Post-intervention blood samples were collected from an antecubital vein into vacutainer tubes containing EDTA after a 12-h overnight fast, and assessment of the basic lipid profile was performed according to previously described procedures $^{(29)}$.

Carotenoids. Samples and standards used for the measurement of carotenoid concentrations were prepared as reported previously $^{(13)}$. Briefly, aliquots of $100 \mu \mathrm{l}$ of post-intervention fasting plasma samples maintained at $-80^{\circ} \mathrm{C}$ were thawed a day before analyses. After being vortexed and centrifuged (3500 rpm, $10 \mathrm{~min}, 4^{\circ} \mathrm{C}$ ), plasma samples were transferred to Eppendorf tubes $(1.5 \mathrm{ml})$ along with $20 \mu \mathrm{l}$ of 2-propanol and $20 \mu \mathrm{l}$ of 
carotenoid standard. Samples were then transferred to a 400- $\mu \mathrm{l}$ fixed well plate (ISOLUTE ${ }^{\circledR}$ SLE +; Biotage) and mixed with $900 \mu \mathrm{l}$ of hexane:isopropanol $(90: 10, \mathrm{v} / \mathrm{v})$. After evaporation under $\mathrm{N}$, the dried samples were reconstituted with $300 \mu \mathrm{l}$ of methanol:dichloromethane (65:35, v/v), shaken for $10 \mathrm{~min}$ and finally transferred into HPLC glass vials for analysis

\section{HPLC}

HPLC-UV analysis ${ }^{(30)}$ of the samples was performed using an Agilent 1260 liquid handling system (Agilent) as described previously ${ }^{(13)}$. Carotenoids of the different samples were separated with a mobile phase consisting of methanol:water (98:2, v/v; eluent A) and methyl-tert-butyl ether (eluent B). Flow rate was set at $1 \mathrm{ml} / \mathrm{min}$, and the gradient elution was as follows: $2 \%$ eluent B (initial), $2 \cdot 0-80 \%$ eluent B (0.0-27.0 min), isocratic $80 \%$ eluent $\mathrm{B}(27 \cdot 0-31.0 \mathrm{~min}), 80 \cdot 0-2 \cdot 0 \%$ eluent $\mathrm{B}$ (31.0-31.1 $\mathrm{min})$ and isocratic $2 \%$ eluent $\mathrm{B}(31.1-34.0 \mathrm{~min})$ Identification of each carotenoid was confirmed with a UV detector $(450 \mathrm{~nm})$ and using retention time and UV spectra $(190-640 \mathrm{~nm})$ of the pure compounds. Data acquisition was carried out using Chemstation software (Agilent).

\section{Statistical analyses}

Data are presented as means and standard deviations unless stated otherwise. Spearman's correlation coefficients were calculated to test for associations among variables. General linear multiple regression analysis was used to examine the effects of predictors of plasma carotenoid concentrations. The LSMEANS option was used with the PROC MIXED procedure to compare plasma carotenoid concentrations of men and women adjusted for intervention, body weight as well as plasma LDL- and HDLcholesterol concentrations. All analyses were performed using the SAS statistical package (9.3; SAS Institute Inc.). Throughout the analyses, a $P$ value $\leq 0.05$ was considered as statistically significant.

\section{Results}

Table 1 presents physical characteristics of men and women who participated in the study. Men had a higher body weight, BMI and a larger waist circumference compared with women. Men were also characterised with higher plasma TAG and lower total and HDL-cholesterol concentrations compared with women, while no significant difference in plasma LDLcholesterol concentrations $(P=0.79)$ was noted between men and women. Energy as well as macronutrient intakes of the participants are also shown in Table 1. Daily energy intake was higher for men than for women (3443 (sD 1687) kJ/d; $P<0.0001)$. Although dietary lipid, carbohydrate and protein intakes were higher in men compared with women, diets of both groups of participants were in line with recommended Canadian dietary guidelines ${ }^{(31)}$, that is the percentage of total energy content from lipids, carbohydrates and proteins were between $20-35$, 45-65 and 10-35\%, respectively.

As illustrated in Fig. 1, women had a lower total carotenoid dietary intake $(-57 \%, P<0 \cdot 0001)$ as well as higher plasma total carotenoid concentrations $(26 \%, P<0.0001)$ compared with men. In addition, all individual carotenoid dietary intakes of women were lower than those of men $(P<0 \cdot 0001$ for all with the exception of $P<0.05$ for $\beta$-cryptoxanthin, Table 1$)$. In contrast, women showed higher plasma $\alpha$-carotene $(17 \%$, $P<0.01), \beta$-carotene $(34 \%, P<0.0001), \beta$-cryptoxanthin $(20 \%$, $P<0.0005)$, lutein $(17 \%, \quad P<0.0005)$, lycopene $(25 \%$, $P<0.0001)$ and zeaxanthin $(17 \%, P<0.05)$ concentrations compared with men (Table 1).

Correlations of physical and metabolic characteristics with plasma carotenoid concentrations are shown in Table 2. We found that a higher body weight, BMI and waist circumference were associated with lower circulating total and individual carotenoid concentrations, with the exception of plasma lutein and zeaxanthin. On the other hand, elevated plasma total-, LDLand HDL-cholesterol concentrations were positively correlated with plasma total as well as with individual carotenoids with the exception of the correlation between plasma zeaxanthin and HDL-cholesterol concentrations which only tended towards significance $(P=0.0538$; Table 2$)$. The cholesterol:HDL-cholesterol ratio was negatively correlated with plasma total carotenoids as well as with $\alpha$-carotene, $\beta$-carotene and lycopene. When men and women were examined separately (online Supplementary Table S2), similar patterns of associations were noted as in the entire group, with most correlations being stronger in men than in women. The positive correlations between individual plasma carotenoids and total- as well as LDL-cholesterol concentrations were all significant in both men and women, with the exception of the association between plasma LDL-cholesterol and lutein in women. On the other hand, plasma HDL-cholesterol was positively associated with all circulating carotenoids with the exception of lutein and zeaxanthin concentrations in men, while circulating HDL-cholesterol concentrations were positively correlated only with total carotenoids, $\alpha$-carotene and lycopene concentrations in women (online Supplementary Table S2). Although total carotenoid dietary intake and plasma concentration were negatively associated, dietary intakes for $\beta$-cryptoxanthin, lutein and lycopene were positively correlated with their respective circulating concentrations in the entire cohort (Table 3). Positive correlations between dietary intakes and circulating concentrations for $\beta$-cryptoxanthin, lutein and lycopene were also noted in both men and women, while $\alpha$-carotene and $\beta$-carotene dietary intakes and plasma concentrations were positively associated in men only (Table 3). There was no association between total carotenoid dietary intake and plasma concentration in men or in women. Also shown in Table 3 are the correlations between dietary and circulating carotenoids adjusted for HDL-cholesterol and body weight. We found that adjusting simultaneously for HDL-cholesterol and body weight strengthened the associations between dietary intakes and circulating concentrations for $\alpha$-carotene, $\beta$-carotene, $\beta$-cryptoxanthin, lutein, lycopene and zeaxanthin but not for total carotenoids. Similar observations are made for $\beta$-cryptoxanthin, lutein and zeaxanthin when men and women are analysed separately (Table 3 ). On the other hand, adjusting correlations for body weight and HDL-cholesterol did not have a noticeable effect on the correlations for $\alpha$-carotene, $\beta$-carotene and lycopene within men or women. 
Table 1. Characteristics of study participants (Mean values and standard deviations)

\begin{tabular}{|c|c|c|c|c|c|}
\hline \multirow[b]{2}{*}{ Variables } & \multicolumn{2}{|c|}{ Women } & \multicolumn{2}{|c|}{ Men } & \multirow[b]{2}{*}{$P$} \\
\hline & Mean & SD & Mean & SD & \\
\hline No. of participants & \multicolumn{2}{|c|}{110} & \multicolumn{2}{|c|}{155} & - \\
\hline Age (years) & $41 \cdot 2$ & $15 \cdot 18$ & $43 \cdot 6$ & 13.9 & 0.17 \\
\hline Weight (kg) & $68 \cdot 8$ & $12 \cdot 8$ & $89 \cdot 3$ & $17 \cdot 0$ & $<0.0001$ \\
\hline BMI $\left(\mathrm{kg} / \mathrm{m}^{2}\right)$ & $25 \cdot 9$ & 4.9 & 28.9 & $5 \cdot 2$ & $<0.0001$ \\
\hline Waist circumference $(\mathrm{cm})$ & $86 \cdot 3$ & $12 \cdot 3$ & $100 \cdot 8$ & $15 \cdot 6$ & $<0.0001$ \\
\hline \multicolumn{6}{|l|}{ Plasma concentrations } \\
\hline Total cholesterol $(\mathrm{mmol} / \mathrm{l})$ & $5 \cdot 14$ & 0.85 & 4.79 & 0.97 & 0.003 \\
\hline TAG (mmol/l) & $1 \cdot 12$ & 0.51 & 1.48 & 0.68 & $<0.0001$ \\
\hline LDL-cholesterol (mmol/l) & $3 \cdot 12$ & 0.72 & $3 \cdot 10$ & 0.86 & 0.79 \\
\hline HDL-cholesterol (mmol/l) & 1.51 & 0.38 & 1.03 & 0.27 & $<0.0001$ \\
\hline Total/HDL-cholesterol & 3.57 & 0.94 & 4.93 & 1.39 & $<0.0001$ \\
\hline$a$-Carotene $(\mu \mathrm{mol} / \mathrm{l})$ & 0.27 & 0.12 & 0.23 & 0.14 & 0.008 \\
\hline$\beta$-Carotene $(\mu \mathrm{mol} / \mathrm{l})$ & 0.59 & 0.28 & 0.44 & 0.20 & $<0.0001$ \\
\hline$\beta$-Cryptoxanthin $(\mu \mathrm{mol} / \mathrm{l})$ & $0 \cdot 18$ & 0.08 & $0 \cdot 15$ & 0.06 & 0.0002 \\
\hline Lycopene $(\mu \mathrm{mol} / \mathrm{l})$ & 0.35 & 0.15 & 0.28 & $0 \cdot 12$ & $<0.0001$ \\
\hline Lutein $(\mu \mathrm{mol} / \mathrm{l})$ & 0.27 & 0.08 & 0.23 & $0 \cdot 10$ & 0.0002 \\
\hline Zeaxanthin $(\mu \mathrm{mol} / \mathrm{l})$ & 0.07 & 0.02 & 0.06 & 0.02 & 0.014 \\
\hline Retinol $(\mu \mathrm{mol} / \mathrm{l})$ & $3 \cdot 12$ & 0.67 & $3 \cdot 36$ & 0.53 & 0.0014 \\
\hline \multicolumn{6}{|l|}{ Dietary intakes } \\
\hline Energy $(\mathrm{kJ} / \mathrm{d})$ & 9855 & 1185 & 13299 & 1966 & $<0.0001$ \\
\hline Lipids (\% energy) & $33 \cdot 2$ & 1.4 & $34 \cdot 3$ & $2 \cdot 2$ & $<0.0001$ \\
\hline Lipids (g/d) & 86.86 & 10.49 & $121 \cdot 18$ & $19 \cdot 21$ & $<0.0001$ \\
\hline Carbohydrates (\% energy) & $52 \cdot 3$ & $2 \cdot 3$ & $49 \cdot 6$ & 0.6 & $<0.0001$ \\
\hline Carbohydrates $(\mathrm{g} / \mathrm{d})$ & 307.68 & $35 \cdot 21$ & 394.51 & 58.92 & $<0.0001$ \\
\hline Proteins (\% energy) & $15 \cdot 8$ & 0.9 & $16 \cdot 2$ & 1.2 & 0.008 \\
\hline Proteins (g/d) & 93.38 & $14 \cdot 2$ & $128 \cdot 7$ & $21 \cdot 3$ & $<0.0001$ \\
\hline$a$-Carotene $(\mathrm{mg} / \mathrm{d})$ & 1.43 & 0.26 & 2.54 & 1.07 & $<0.0001$ \\
\hline$\beta$-Carotene $(\mathrm{mg} / \mathrm{d})$ & $6 \cdot 34$ & $2 \cdot 16$ & $10 \cdot 10$ & 2.58 & $<0.0001$ \\
\hline$\beta$-Cryptoxanthin $(\mathrm{mg} / \mathrm{d})$ & 0.75 & 0.46 & 0.96 & 0.75 & 0.013 \\
\hline Lycopene $(\mathrm{mg} / \mathrm{d})$ & 8.01 & 1.47 & $13 \cdot 01$ & $5 \cdot 06$ & $<0.0001$ \\
\hline Lutein + zeaxanthin $(\mathrm{mg} / \mathrm{d})$ & 3.73 & 1.33 & 5.28 & 1.81 & $<0.0001$ \\
\hline
\end{tabular}

Multiple linear regression analysis (Table 4) revealed a significant portion of the variance in plasma total carotenoid concentration (adjusted $R^{2} 0 \cdot 547, P<0 \cdot 0001$ ). Age, female sex, LDL-cholesterol, HDL-cholesterol, TAG and dietary total carotenoid intake were positively associated with plasma total carotenoid concentrations. On the other hand, body weight was negatively associated with plasma total carotenoid concentrations. When men and women were analysed separately (Table 4), the same list of variables was found to be associated with circulating carotenoids in men (adjusted $R^{2} 0.565$, $P<0 \cdot 0001)$, whereas only LDL-cholesterol, HDL-cholesterol and dietary total carotenoid intake were positively associated and body weight negatively associated with plasma total carotenoid concentrations in women (adjusted $R^{2} 0 \cdot 440, P<0 \cdot 0001$ ).

Considering that physical and metabolic characteristics were found to be associated with circulating carotenoid concentrations, we investigated whether differences in body weight as well as in plasma LDL- or HDL-cholesterol concentrations between men and women could explain the sex difference observed in plasma carotenoid concentrations. As shown in Fig. 2, plasma total carotenoid concentrations remained higher in women compared with men after statistical adjustments for LDL-cholesterol $(P<0.0001)$, whereas adjusting for body weight reduced the sex difference in circulating carotenoid concentrations (from 20 to $9 \%$ in favour of women), but this difference remained statistically significant $(P<0 \cdot 05)$. On the other hand, after adjustment for plasma HDL-cholesterol concentrations, circulating total carotenoid concentrations were no longer different $(P=0.66$, Fig. 2), despite significantly lower dietary total carotenoid intake in women than in men $(-36 \%$, $P<0 \cdot 0001)$. After the simultaneous statistical adjustment for plasma HDL-cholesterol concentrations and body weight, the differences in plasma $\beta$-carotene, $\beta$-cryptoxanthin, lutein, lycopene and zeaxanthin concentrations, but not $\alpha$-carotene, were no longer significant. Similar results were obtained when statistical adjustments of specific plasma carotenoid concentrations were performed, that is, the adjustment for LDL-cholesterol had no impact on the sex difference in plasma $\alpha$-carotene, $\beta$-carotene, $\beta$-cryptoxanthin, lutein, lycopene and zeaxanthin concentrations, with women still showing higher values after the adjustment when compared with men (online Supplementary Table S3). When adjustment for body weight was performed, the differences in plasma $\alpha$-carotene, lycopene and zeaxanthin concentrations were no longer significant, while those of $\beta$-carotene, $\beta$-cryptoxanthin and lutein concentrations were still higher in women. Finally, $\beta$-carotene, $\beta$-cryptoxanthin, lutein, lycopene and zeaxanthin concentrations were no longer statistically different between men and women, but plasma $\alpha$-carotene concentration was higher in men after adjustment for plasma HDL-cholesterol concentrations either alone or with 
(a)

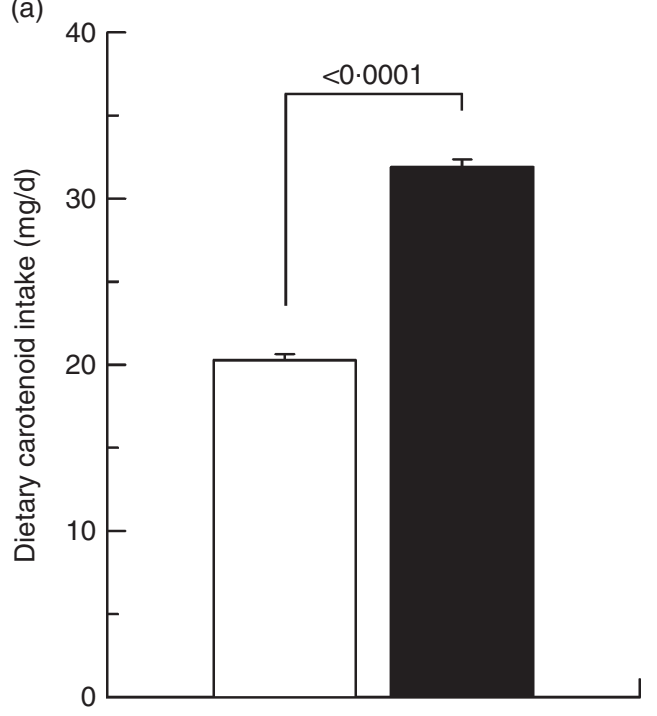

(b)

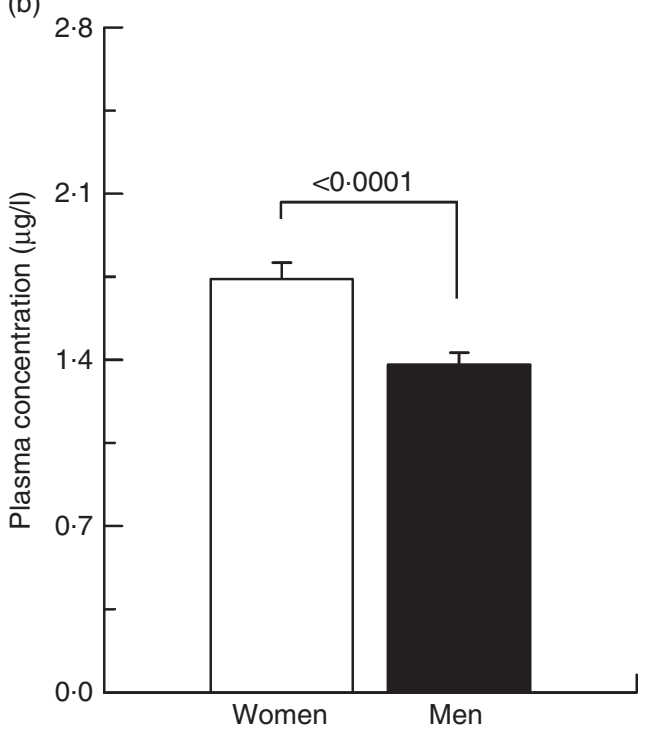

Fig. 1. Carotenoid (a) dietary intakes and (b) plasma concentrations in men $(\square)$ and women ( $\square$ ). body weight. Furthermore, statistical adjustment for the intervention each participant was enrolled in had no effect on the sex difference in circulating total carotenoids as well as in $\alpha$-carotene, $\beta$-carotene, $\beta$-cryptoxanthin and lycopene concentrations that remained higher in women compared with men following the adjustment procedure (data not shown). On the other hand, plasma lutein and zeaxanthin concentrations were no longer significantly different between men and women after statistical adjustment for the intervention they were enrolled in.

\section{Discussion}

Results of the present study indicate that variations in circulating HDL-cholesterol concentrations are a significant correlate of the difference in plasma carotenoid concentrations observed between men and women. These results are in line with previous observations that identified lipoprotein cholesterol concentrations as determinants of circulating carotenoids ${ }^{(18,32,33)}$, and the present study extends these contributions to the sex difference in blood carotenoids.

Due to their hydrophobic nature, lipids are transported in the circulation by lipoproteins, namely, chylomicrons, VLDL, LDL and $\mathrm{HDL}^{(19)}$. Carotenoids are also hydrophobic molecules that are transported in varying proportions by lipoproteins. For instance, $\alpha$-carotene, $\beta$-carotene and lycopene are present in the hydrophobic core of VLDL (10-16\%), LDL (58-73\%) and HDL $(17-26 \%)^{(19)}$. On the other hand, xanthophylls, which are more polar carotenoids, are also present on the surface of lipoproteins and distributed in VLDL (16\%), LDL (31\%) and HDL (53\%) for lutein and zeaxanthin, while $\beta$-cryptoxanthin is distributed in VLDL (16\%) and equally in LDL (40\%) and HDL $(40 \%)^{(19)}$. In line with these observations, and as previously reported $^{(34)}$, we found that plasma total carotenoid concentrations were positively correlated with circulating LDL- and HDL-cholesterol concentrations in men and women. On the other hand, there are known sex differences in lipid and lipoprotein metabolism, with women usually showing lower LDL-cholesterol and higher HDL-cholesterol concentrations compared with men ${ }^{(35)}$. Although plasma LDL-cholesterol

Table 2. Spearman correlations between physical and metabolic characteristics and plasma carotenoid concentrations in all participants

\begin{tabular}{|c|c|c|c|c|c|c|c|}
\hline \multirow[b]{2}{*}{ Variables } & \multicolumn{7}{|c|}{ Plasma carotenoid concentrations } \\
\hline & Total & a-Carotene & $\beta$-Cryptoxanthin & Lycopene & Lutein & $\beta$-Carotene & Zeaxanthin \\
\hline Age (years) & 0.08 & -0.04 & 0.05 & -0.03 & $0 \cdot 17^{\star \star}$ & 0.10 & $0.34 † \dagger$ \\
\hline Body weight & $-0.47 \dagger \dagger$ & $-0.45 \dagger \dagger$ & $-0.22 \dagger$ & $-0.41 \dagger \dagger$ & $-0 \cdot 16^{\star \star}$ & $-0.40 \dagger \dagger$ & -0.06 \\
\hline BMI $\left(\mathrm{kg} / \mathrm{m}^{2}\right)$ & $-0.42 \dagger \dagger$ & $-0.47 \dagger \dagger$ & $-0.19 \dagger$ & $-0.40 \dagger \dagger$ & -0.04 & $-0.36 \dagger \dagger$ & 0.07 \\
\hline Waist circumference & $-0.46 \dagger \dagger$ & $-0.50 \dagger \dagger$ & $-0.22 \dagger$ & $-0.42 \dagger \dagger$ & -0.04 & $-0.40 \dagger \dagger$ & 0.06 \\
\hline Total cholesterol & $0.57 † \dagger$ & $0.40 \dagger †$ & $0.47 \dagger †$ & $0.44 † \dagger$ & $0.33 † \dagger$ & $0.39 † \dagger$ & $0.36 † \dagger$ \\
\hline TAG & $-0.22 \dagger$ & $-0.29 \dagger \dagger$ & -0.08 & $-0 \cdot 13^{*}$ & 0.07 & $-0.28 \dagger \dagger$ & $0 \cdot 14^{*}$ \\
\hline LDL-cholesterol & $0.49 \dagger \dagger$ & $0.34 † \dagger$ & $0.45 † \dagger$ & $0.34 † \dagger$ & $0.26 \dagger \dagger$ & $0.35 \dagger \dagger$ & $0.30 † \dagger$ \\
\hline HDL-cholesterol & $0.50 \dagger \dagger$ & $0.45 \dagger \dagger$ & $0.27 \dagger \dagger$ & $0.42 \dagger \dagger$ & $0.22 \dagger$ & $0.42 \dagger \dagger$ & $0.12 \ddagger$ \\
\hline Total/HDL-cholesterol & $-0 \cdot 17^{\star \star}$ & $-0.22 \dagger$ & 0.01 & $-0 \cdot 16^{\star \star}$ & -0.02 & $-0 \cdot 18^{\star \star \star}$ & 0.09 \\
\hline
\end{tabular}

* $P \leq 0.05 ;{ }^{* *} P \leq 0.01 ;{ }^{* \star *} P \leq 0.005$.

† $P \leq 0.0005 ;$ †† $P \leq 0.0001$.

$\ddagger P=0.0538$. 
Table 3. Spearman correlations between carotenoid dietary intakes and plasma concentrations

\begin{tabular}{|c|c|c|c|c|c|c|c|}
\hline & Total & a-Carotene & $\beta$-Carotene & $\beta$-Cryptoxanthin & Lutein§ & Lycopene & Zeaxanthin§ \\
\hline \multicolumn{8}{|l|}{ Unadjusted } \\
\hline Men & 0.12 & $0.40 \dagger$ & $0.34 \dagger$ & $0 \cdot 28^{\star \star \star}$ & $0.42 \dagger$ & $0.51 \dagger$ & $0.22^{\star \star}$ \\
\hline Women & -0.13 & $-0 \cdot 20^{\star}$ & -0.07 & $0.44 \dagger$ & $0 \cdot 33^{\star \star \star}$ & $0.26^{\star \star}$ & $0.17 \ddagger$ \\
\hline All & $-0.26 \dagger$ & -0.04 & -0.04 & $0.31 \dagger$ & $0 \cdot 21^{* * *}$ & $0 \cdot 15^{\star}$ & $0.11 \ddagger$ \\
\hline \multicolumn{8}{|c|}{ Adjusted for body weight and HDL-cholesterol } \\
\hline Men & 0.08 & $0.24^{*}$ & $0.34 \dagger$ & $0.45 \dagger$ & $0.48 \dagger$ & $0.51 \dagger$ & $0.48 \dagger$ \\
\hline Women & 0.13 & 0.02 & 0.08 & $0.52 \dagger$ & $0.54 \dagger$ & $0.26^{\star *}$ & $0.33^{\star \star \star}$ \\
\hline All & 0.09 & $0.25 \dagger$ & $0.26 \dagger$ & $0.45 \dagger$ & $0.46 \dagger$ & $0.41 \dagger$ & $0 \cdot 21^{\star \star}$ \\
\hline
\end{tabular}

${ }^{\star} P \leq 0.05 ;{ }^{* \star} P \leq 0.01 ;{ }^{* \star *} P \leq 0.0005$.

$\dagger P \leq 0.0001$.

$\ddagger P=0.07$.

$\S$ Dietary (lutein + zeaxanthin) intake was used for the analyses.

Table 4. Multivariate linear regression analysis on predictors associated with plasma total carotenoids in men and women

( $\beta$-Coefficients and standard errors)

\begin{tabular}{|c|c|c|c|c|}
\hline \multirow[b]{2}{*}{ Variables } & \multicolumn{4}{|c|}{ Plasma carotenoids } \\
\hline & $\beta$ & SE & $t$ & $P$ \\
\hline \multicolumn{5}{|l|}{ All ( $n$ 265) } \\
\hline Age & 0.002 & 0.001 & $1 \cdot 19$ & $0 \cdot 23$ \\
\hline Sex & 0.217 & 0.075 & 2.91 & 0.0039 \\
\hline Body weight & -0.009 & 0.002 & -5.56 & 0.0001 \\
\hline LDL-cholesterol & 0.277 & 0.029 & 9.68 & 0.0001 \\
\hline HDL-cholesterol & 0.524 & 0.077 & $6 \cdot 81$ & 0.0001 \\
\hline TAG & 0.069 & 0.040 & $1 \cdot 71$ & 0.09 \\
\hline Dietary carotenoids & $2 \cdot 43 \mathrm{E}-5$ & $4 \cdot 81 \mathrm{E}-6$ & 5.07 & 0.0001 \\
\hline \multicolumn{5}{|l|}{ Men $(n$ 155) } \\
\hline Age & 0.002 & 0.002 & 0.91 & 0.3664 \\
\hline Body weight & $-8 \cdot 58 E-3$ & $1.59 \mathrm{E}-3$ & -5.41 & 0.0001 \\
\hline LDL-cholesterol & 0.238 & 0.029 & $8 \cdot 32$ & 0.0001 \\
\hline HDL-cholesterol & 0.586 & 0.103 & $5 \cdot 70$ & 0.0001 \\
\hline TAG & 0.119 & 0.040 & 2.98 & 0.0033 \\
\hline Dietary carotenoids & $2 \cdot 22 \mathrm{E}-5$ & $5 \cdot 32 \mathrm{E}-6$ & $4 \cdot 17$ & 0.0001 \\
\hline \multicolumn{5}{|l|}{ Women (n 110) } \\
\hline Age & $7 \cdot 97 \mathrm{E}-4$ & 0.003 & 0.27 & $0 \cdot 79$ \\
\hline Body weight & -0.014 & 0.004 & -3.39 & 0.0010 \\
\hline LDL-cholesterol & 0.385 & 0.063 & $6 \cdot 13$ & 0.0001 \\
\hline HDL-cholesterol & 0.448 & 0.135 & 3.33 & 0.0012 \\
\hline TAG & -0.080 & 0.089 & -0.90 & 0.37 \\
\hline Dietary carotenoids & $4 \cdot 26 \mathrm{E}-5$ & $1 \cdot 31 \mathrm{E}-5$ & $3 \cdot 26$ & 0.0015 \\
\hline
\end{tabular}

concentrations were similar between men and women of the present study, the latter had significantly higher circulating HDL-cholesterol concentrations suggesting a higher carotenoid transport capacity that may contribute to the higher circulating carotenoid concentrations in women compared with men. Our results support such a contribution, as the difference in plasma total carotenoid concentrations was eliminated when the latter was adjusted for plasma HDL-cholesterol concentrations. Interestingly, this lack of difference in plasma carotenoids was noted even if men had a significantly higher dietary carotenoid intake compared with women, suggesting lower incorporation of dietary carotenoids in HDL in men. A possible explanation for this observation could be related to differences in the physical characteristics of lipoprotein particles such as LDL and HDL between men and women. Indeed, besides differences in circulating concentrations, men have also been reported to have smaller, denser LDL and HDL particles compared with women $^{(35-38)}$. In addition, small, dense LDL and HDL particles have been characterised with diminished carotenoid content $^{(32)}$. Thus, in the present study, although women have a lower dietary carotenoid intake than men, they may incorporate a greater proportion of their carotenoid intake into larger LDL and HDL particles, yielding higher plasma concentrations. Unfortunately, lipoprotein particle size and density measurements were not available in study participants, but we found that men had higher TAG and cholesterol:HDL-cholesterol ratio compared with women, which are, respectively, good correlates of the presence of small, dense $\mathrm{LDL}^{(36,39)}$ and $\mathrm{HDL}^{(37)}$ particles. Quantification of the carotenoid content of plasma LDL and HDL particles of study participants would also have been interesting to analyse.

Obesity is also associated, among others, with lower circulating carotenoid concentration ${ }^{(14)}$. Because of their lipophilic character, a greater uptake of carotenoids by adipose tissue may contribute to lowering plasma values in obese individuals ${ }^{(19)}$. The negative impact of body fat on circulating carotenoids has 

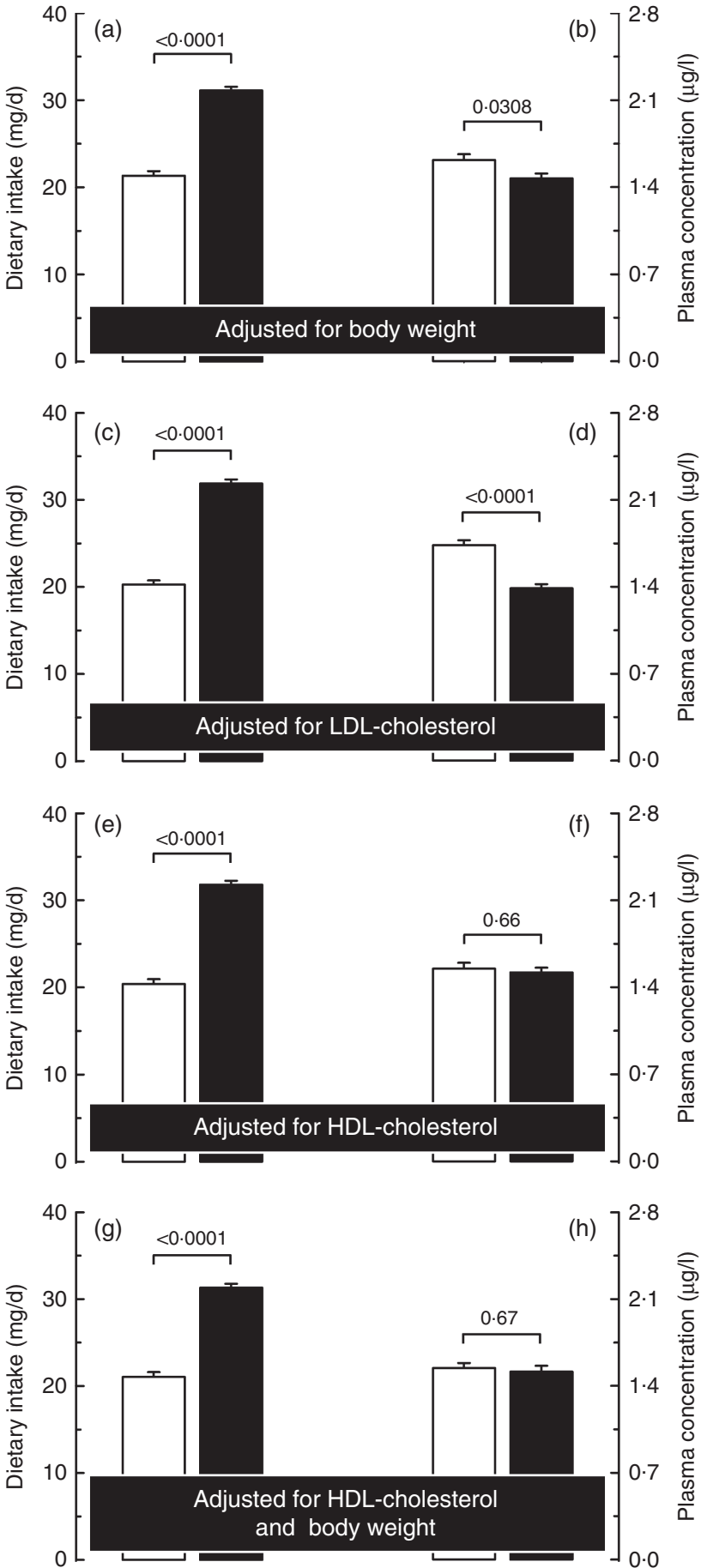

Fig. 2. Carotenoid dietary intakes (a, c, e and g) and plasma concentrations (b, d, f and h) in men $(\square$ ) and women $(\square$ ) adjusted for body weight (a and b), plasma LDL-cholesterol (c and d) and HDL-cholesterol concentrations (e and f) as well as for HDL-cholesterol and body weight simultaneously ( $\mathrm{g}$ and $\mathrm{h}$ ).

been recently underlined in women, as low serum $\alpha$-carotene concentrations were found to be negatively correlated with BMI and body fat in women even after adjustment for age and dietary intake ${ }^{(40)}$. Our results also support the negative influence of obesity and abdominal adipose tissue accumulation with regard to circulating carotenoids, as the sex difference in plasma carotenoid concentrations was reduced when values were adjusted for body weight or waist circumference (data not shown for the latter). When specific carotenoids were examined, we found that the sex difference in $\alpha$-carotene, lycopene and zeaxanthin was eliminated by statistical adjustment for body weight (online Supplementary Table S3). Carotenoids are potent antioxidants ${ }^{(41)}$, and the higher oxidative stress in men $^{(42)}$ and in obese individuals ${ }^{(43,44)}$ could be responsible for the apparent lower ratio of circulating concentrations to dietary intake of carotenoids in men compared with women. However, we did not characterise the oxidative stress profile of our study participants and therefore could not test this hypothesis.

Dietary variables have also been shown to influence circulating carotenoid concentrations. First and foremost, dietary carotenoid intake is a significant contributor to circulating carotenoid. The significant correlations between carotenoid dietary intakes and circulating concentrations we report herein are supportive of this contribution. In the present study, men have a higher dietary carotenoid intake than women, an observation somewhat contradictory with their lower plasma carotenoid concentrations compared with women. However, as recently reviewed ${ }^{(45)}$, the correlations between both measures have been reported to be weak to moderate. In fact, $\beta$-cryptoxanthin shows the strongest associations between dietary intake and plasma concentration ${ }^{(45)}$, whereas such a significant correlation is not as strong and even absent with $\beta$-carotene ${ }^{(46,47)}$. Furthermore, there is evidence that some individuals can be characterised as responders and non- or low responders to $\beta$-carotene intake ${ }^{(48-51)}$, that is, the changes in circulating $\beta$-carotene concentration following the consumption of $\beta$-carotene are variable. Whether such processes can contribute to the difference in plasma carotenoids noted between men and women could not be investigated in the context of our study. In addition, fat intake has been shown to increase the bioavailability of carotenoids by creating a favourable environment for the absorption and transportation of carotenoids through the formation of micelles ${ }^{(19,52)}$. However, a major influence of fat intake on carotenoid absorption in the present study seems unlikely, as men who had a significantly higher fat intake compared with women were also those showing lower plasma carotenoid concentrations. In contrast, dietary fibre intake has been shown to decrease the bioavailability of dietary carotenoids by limiting their absorption through a decrease in the formation of micelles ${ }^{(53)}$ and by limiting the contact of circulating micelles with the intestinal wall ${ }^{(54)}$. Again, results of the present study do not support a significant role of dietary fibre intake in the sex difference in plasma carotenoids, as women had higher fibre intake compared with men but were also those displaying higher plasma carotenoid concentrations.

Several proteins are implicated in dietary carotenoid absorption, including the scavenger receptor class B type 1 , cluster determinant 36, Niemann-Pick C1-like 1 protein and ATPbinding cassette $\mathrm{A} 1^{(52)}$. Variations in the activity or expression of these proteins could therefore contribute to the interindividual variability in carotenoid bioavailability. Accordingly, variants of genes involved in carotenoid absorption have been related to the bioavailability of $\beta$-carotene ${ }^{(55)}$, lutein ${ }^{(56)}$ and 
lycopene ${ }^{(57)}$. Our study did not explore the contribution of proteins (or their genetic variants) involved in absorption and transport of dietary carotenoids in the difference in plasma carotenoid concentrations. Future research should explore the relevance of genetic polymorphisms in the explanation of the sex-related variability in dietary carotenoid bioavailability.

The strengths of the present study include the analysis of data from a series of fully controlled nutritional intervention studies in which all foods were provided to the participants. This allowed a more precise assessment of dietary intakes than the usual self-reported data from dietary questionnaires. In addition, there was a large variability in carotenoid intakes (13.6$51.3 \mathrm{mg} / \mathrm{d}$ ) between participants, allowing for greater representation of intakes. Our study also has limitations that must be acknowledged. First, we compiled data from intervention studies that were not primarily designed to study carotenoid bioavailability. For instance, although there were differences in the carotenoid content of the different diets, the intakes of different carotenoids were significantly higher than the median carotenoid intakes for women and men, that is, 5.47 and $6.88 \mathrm{mg} / \mathrm{d}$, respectively ${ }^{(58)}$. Extending the dietary carotenoid range to lower intakes may have allowed us to investigate whether a potential plateau of absorption of dietary carotenoid contributed to the difference noted in plasma carotenoid concentrations between men and women or whether the latter is also present at lower dietary carotenoid intakes. Second, there are also variations in the proportion of individual carotenoids consumed within each intervention which may affect total carotenoids in circulation. Furthermore, the carotenoid contents of the fully controlled diets were calculated using the 2010 Canadian Nutrient File (http:// webprod3.hc-sc.gc.ca/cnf-fce/index-eng.jsp), although direct measures of the carotenoid content of the different diets/meals consumed would have given an even more precise measure of the carotenoid intake of the participants. However, such measurements would have been extremely costly and timeconsuming. Finally, our study does not take into account genetic characteristics of subjects or even seasonal variations in the carotenoid content of foods consumed, which are also factors that likely affect carotenoid metabolism in humans. The potential contributions of these factors in our results merit further investigations.

In conclusion, the present study demonstrates that HDLcholesterol and to a lesser extent body weight are correlates of the difference in plasma carotenoid concentrations observed between men and women. Our results suggest that using crude circulating carotenoid concentrations without consideration for sex differences in plasma lipoprotein concentrations or adiposity could lead to under-/over-estimation of carotenoid intake in men and women. A better understanding of the factors affecting plasma carotenoid concentrations will lead to a more accurate use of nutritional biomarkers for the assessment of food intakes. In this regard, our results suggest that physical and metabolic characteristics of an individual should be taken into account when using plasma carotenoids to validate dietary questionnaires, including those measuring FAV intakes and therefore avoid mistakenly concluding to under- or overreporting of dietary carotenoid and/or FAV intakes in men and women.

\section{Acknowledgements}

The authors would like to acknowledge the contribution of Pascal Dubé of the Institute of Nutrition and Functional Foods for the measurements of plasma carotenoid concentrations. The authors would also like to acknowledge the contributions of nurses and other research professionals as well as subjects who participated in the dietary interventions without whom, no clinical research would be possible.

Studies were made possible by grants from the Canadian Institutes of Health Research (MOP-68866, MOP-84568 and FHG-129921), the Natural Sciences and Engineering Research Council of Canada, the Dairy Farmers of Canada, the Canadian Dairy Commission, Novalait Inc., Dairy Australia, Agriculture and Agri-Food Canada, the Canola Council of Canada, the Flax Council of Canada, Dow Agrosciences, the Western Grains Research Foundation of Canada, the National Center for Research Resources (UL1 RR033184) and the National Center for Advancing Translational Sciences (UL1 TR000127). Funders of the studies had no role in the design, analysis or writing of the present article.

C. C. has received research funding from the Canadian Cranberry Growers Coalition and McCormick Science Institute and received honoraria or travel expense reimbursements from the Berry Health Benefits Symposium, Ocean Spray Cranberries Inc. and Mott's Canada. C. C. and B. L. have received research funding from Atrium Innovations. B. L. has received research funding from the Danone Institute and honoraria from Unilever, Danone and the Dairy Farmers of Canada. B. L. is Chair in Nutrition and Cardiovascular Health, supported in part by Provigo/Loblaws. B. L. and P. C. have received research grants from the Dairy Farmers of Canada and Dairy Australia. The funders were not involved in the design, conduct, management, data collection and analysis, or preparation and review of the manuscript.

The authors' responsibilities are as follows: T. A., C. C., S. L., M.-C. V., P. C. and B. L.: research design. P. C.: medical supervision of study participants. C. C., S. L., M.-C. V., P. C. and B. L.: data acquisition. T. A.: analysis and interpretation of the data and drafting of the manuscript. C. C., M.-C. V., P. C., S. L. and B. L.: critical revision of the manuscript for important intellectual content. All authors read and approved the final manuscript.

The authors were not aware of any conflicts of interest related to this article.

\section{Supplementary material}

For supplementary material/s referred to in this article, please visit https://doi.org/10.1017/S0007114518003045

\section{References}

1. Subar AF (2004) Developing dietary assessment tools. J Am Diet Assoc 104, 769-770.

2. Hebert JR, Hurley TG, Steck SE, et al. (2014) Considering the value of dietary assessment data in informing nutrition-related health policy. Adv Nutr 5, 447-455. 
3. Subar AF, Kipnis V, Troiano RP, et al. (2003) Using intake biomarkers to evaluate the extent of dietary misreporting in a large sample of adults: the OPEN study. Am J Epidemiol 158, 1-13.

4. Bihuniak JD, Simpson CA, Sullivan RR, et al. (2013) Dietary protein-induced increases in urinary calcium are accompanied by similar increases in urinary nitrogen and urinary urea: a controlled clinical trial. J Acad Nutr Diet 113, 447-451.

5. Ainslie P, Reilly T \& Westerterp K (2003) Estimating human energy expenditure: a review of techniques with particular reference to doubly labelled water. Sports Med 33, 683-698.

6. Redman LM, Kraus WE, Bhapkar M, et al. (2014) Energy requirements in nonobese men and women: results from CALERIE. Am J Clin Nutr 99, 71-78.

7. Baldrick FR, Woodside JV, Elborn JS, et al. (2011) Biomarkers of fruit and vegetable intake in human intervention studies: a systematic review. Crit Rev Food Sci Nutr 51, 795-815.

8. Maiani G, Caston MJ, Catasta G, et al. (2009) Carotenoids: actual knowledge on food sources, intakes, stability and bioavailability and their protective role in humans. Mol Nutr Food Res 53, Suppl. 2, S194-S218.

9. Crowe FL, Roddam AW, Key TJ, et al. (2011) Fruit and vegetable intake and mortality from ischaemic heart disease: results from the European Prospective Investigation into Cancer and Nutrition (EPIC)-Heart study. Eur Heart $J$ 32, 1235-1243.

10. Yusuf S, Hawken S, Ounpuu S, et al. (2004) Effect of potentially modifiable risk factors associated with myocardial infarction in 52 countries (the INTERHEART study): casecontrol study. Lancet 364, 937-952.

11. Carter P, Gray LJ, Troughton J, et al. (2010) Fruit and vegetable intake and incidence of type 2 diabetes mellitus: systematic review and meta-analysis. $\mathrm{Br}$ Med J 341, c4229.

12. Hastert TA, Beresford SA, Patterson RE, et al. (2013) Adherence to WCRF/AICR cancer prevention recommendations and risk of postmenopausal breast cancer. Cancer Epidemiol Biomarkers Prev 22, 1498-1508.

13. Couillard C, Lemieux S, Vohl MC, et al. (2016) Carotenoids as biomarkers of fruit and vegetable intake in men and women. Br J Nutr 116, 1206-1215.

14. Gruber M, Chappell R, Millen A, et al. (2004) Correlates of serum lutein + zeaxanthin: findings from the Third National Health and Nutrition Examination Survey. J Nutr 134, 2387-2394.

15. Al-Delaimy WK, van Kappel AL, Ferrari P, et al. (2004) Plasma levels of six carotenoids in nine European countries: report from the European Prospective Investigation into Cancer and Nutrition (EPIC). Public Health Nutr 7, 713-722.

16. Mares JA, LaRowe TL, Snodderly DM, et al. (2006) Predictors of optical density of lutein and zeaxanthin in retinas of older women in the Carotenoids in Age-Related Eye Disease Study, an ancillary study of the Women's Health Initiative. Am J Clin Nutr 84, 1107-1122.

17. Woodside JV, Young IS, Gilchrist SE, et al. (2013) Factors associated with serum/plasma concentrations of vitamins $\mathrm{A}, \mathrm{C}, \mathrm{E}$ and carotenoids in older people throughout Europe: the EUREYE study. Eur J Nutr 52, 1493-1501.

18. Moran R, Nolan JM, Stack J, et al. (2017) Non-dietary correlates and determinants of plasma lutein and zeaxanthin concentrations in the Irish population. J Nutr Health Aging 21, 254-261.

19. Parker RS (1996) Absorption, metabolism, and transport of carotenoids. Fed Am Soc Exp Biol J 10, 542-551.

20. George SM, Thompson FE, Midthune D, et al. (2012) Strength of the relationships between three self-reported dietary intake instruments and serum carotenoids: the Observing Energy and Protein Nutrition (OPEN) Study. Public Health Nutr 15, 1000-1007.
21. Lacroix E, Charest A, Cyr A, et al. (2012) Randomized controlled study of the effect of a butter naturally enriched in trans fatty acids on blood lipids in healthy women. Am J Clin Nutr 95, 318-325.

22. Jones PJ, Senanayake VK, Pu S, et al. (2014) DHA-enriched high-oleic acid canola oil improves lipid profile and lowers predicted cardiovascular disease risk in the canola oil multicenter randomized controlled trial. Am J Clin Nutr 100, 88-97.

23. Bédard A, Riverin M, Dodin S, et al. (2012) Sex differences in the impact of the Mediterranean diet on cardiovascular risk profile. Br J Nutr 108, 1428-1434.

24. Richard C, Couture P, Desroches S, et al. (2012) Effect of the Mediterranean diet with and without weight loss on surrogate markers of cholesterol homeostasis in men with the metabolic syndrome. Br J Nutr 107, 705-711.

25. Labonté ME, Couture P, Paquin P, et al. (2011) Comparison of the impact of trans fatty acids from ruminant and industrial sources on surrogate markers of cholesterol homeostasis in healthy men. Mol Nutr Food Res 55, Suppl. 2, S241-S247.

26. Willett WC, Sacks F, Trichopoulou A, et al. (1995) Mediterranean diet pyramid: a cultural model for healthy eating. $A m J$ Clin Nutr 61, 1402S-1406S.

27. Gray-Donald K, Jacobs-Starkey L \& Johnson-Down L (2000) Food habits of Canadians: reduction in fat intake over a generation. Can J Public Health 91, 381-385.

28. van der Kooy K \& Seidell JC (1993) Techniques for the measurement of visceral fat: a practical guide. Int J Obes Relat Metab Disord 17, 187-196.

29. Goulet J, Lamarche B, Nadeau G, et al. (2003) Effect of a nutritional intervention promoting the Mediterranean food pattern on plasma lipids, lipoproteins and body weight in healthy French-Canadian women. Atherosclerosis 170, 115124 .

30. Gleize B, Steib M, Andre M, et al. (2012) Simple and fast HPLC method for simultaneous determination of retinol, tocopherols, coenzyme $\mathrm{Q}(10)$ and carotenoids in complex samples. Food Chem 134, 2560-2564.

31. Health Canada (2011) Eating well with Canada's Food Guide. http://www.hc-sc.gc.ca/fn-an/food-guide-aliment/ordercommander/index-eng.php\#a4 (accessed August 2018).

32. Goulinet S \& Chapman MJ (1997) Plasma LDL and HDL subspecies are heterogenous in particle content of tocopherols and oxygenated and hydrocarbon carotenoids. Relevance to oxidative resistance and atherogenesis. Arterioscler Thromb Vasc Biol 17, 786-796.

33. Vioque J, Weinbrenner T, Asensio L, et al. (2007) Plasma concentrations of carotenoids and vitamin $\mathrm{C}$ are better correlated with dietary intake in normal weight than overweight and obese elderly subjects. Br J Nutr 97, 977-986.

34. Wang L, Gaziano JM, Norkus EP, et al. (2008) Associations of plasma carotenoids with risk factors and biomarkers related to cardiovascular disease in middle-aged and older women. $\mathrm{AmJ}$ Clin Nutr 88, 747-754

35. Wang X, Magkos F \& Mittendorfer B (2011) Sex differences in lipid and lipoprotein metabolism: it's not just about sex hormones. J Clin Endocrinol Metab 96, 885-893.

36. Lemieux I, Pascot A, Lamarche B, et al. (2002) Is the gender difference in LDL size explained by the metabolic complications of visceral obesity? Eur J Clin Invest 32, 909-917.

37. Pascot A, Lemieux I, Bergeron J, et al. (2002) HDL particle size: a marker of the gender difference in the metabolic risk profile. Atherosclerosis 160, 399-406.

38. Magkos F, Mohammed BS \& Mittendorfer B (2008) Effect of obesity on the plasma lipoprotein subclass profile in normoglycemic and normolipidemic men and women. Int $J$ Obes (Lond) 32, 1655-1664. 
39. St-Pierre AC, Cantin B, Dagenais GR, et al. (2004) The triglyceride/high-density lipoprotein cholesterol ratio, the small dense low-density lipoprotein phenotype, and ischemic heart disease risk. Metab Syndr Relat Disord 2, 57-64.

40. Nuss ET, Valentine AR, Zhang Z, et al. (2017) Serum carotenoid interactions in premenopausal women reveal alphacarotene is negatively impacted by body fat. Exp Biol Med (Maywood) 242, 1262-1270.

41. Fiedor J \& Burda K (2014) Potential role of carotenoids as antioxidants in human health and disease. Nutrients 6, 466-488.

42. Kaya A, Uzunhasan I, Baskurt M, et al. (2010) Oxidative status and lipid profile in metabolic syndrome: gender differences. Metab Syndr Relat Disord 8, 53-58.

43. Couillard C, Ruel G, Archer WR, et al. (2005) Circulating levels of oxidative stress markers and endothelial adhesion molecules in men with abdominal obesity. J Clin Endocrinol Metab 90, 6454-6459.

44. Keaney JF Jr, Larson MG, Vasan RS, et al. (2003) Obesity and systemic oxidative stress: clinical correlates of oxidative stress in the Framingham Study. Arterioscler Thromb Vasc Biol 23, 434-439.

45. Burrows TL, Williams R, Rollo M, et al. (2015) Plasma carotenoid levels as biomarkers of dietary carotenoid consumption: a systematic review of the validation studies. $J$ Nutr Intermed Metab 2, 15-64.

46. Forman MR, Lanza E, Yong LC, et al. (1993) The correlation between two dietary assessments of carotenoid intake and plasma carotenoid concentrations: application of a carotenoid food-composition database. Am J Clin Nutr 58, 519-524.

47. Hickenbottom SJ, Follett JR, Lin Y, et al. (2002) Variability in conversion of beta-carotene to vitamin A in men as measured by using a double-tracer study design. Am J Clin Nutr 75, 900-907.

48. Bowen PE, Garg V, Stacewicz-Sapuntzakis M, et al. (1993) Variability of serum carotenoids in response to controlled diets containing six servings of fruits and vegetables per day. Ann N Y Acad Sci 691, 241-243.
49. Borel P, Tyssandier V, Mekki N, et al. (1998) Chylomicron beta-carotene and retinyl palmitate responses are dramatically diminished when men ingest beta-carotene with mediumchain rather than long-chain triglycerides. J Nutr $\mathbf{1 2 8}$, 1361-1367.

50. Lin Y, Dueker SR, Burri BJ, et al. (2000) Variability of the conversion of beta-carotene to vitamin A in women measured by using a double-tracer study design. Am J Clin Nutr $\mathbf{7 1}$, $1545-1554$

51. Johnson EJ, Suter PM, Sahyoun N, et al. (1995) Relation between beta-carotene intake and plasma and adipose tissue concentrations of carotenoids and retinoids. Am J Clin Nutr 62, 598-603.

52. Reboul E (2013) Absorption of vitamin A and carotenoids by the enterocyte: focus on transport proteins. Nutrients $\mathbf{5}$, 3563-3581.

53. Yeum KJ \& Russell RM (2002) Carotenoid bioavailability and bioconversion. Annu Rev Nutr 22, 483-504.

54. van Het Hof KH, West CE, Weststrate JA, et al. (2000) Dietary factors that affect the bioavailability of carotenoids. $J$ Nutr 130, 503-506.

55. Borel P, Desmarchelier C, Nowicki M, et al. (2015) A combination of single-nucleotide polymorphisms is associated with interindividual variability in dietary beta-carotene bioavailability in healthy men. J Nutr 145, 1740-1747.

56. Borel P, Desmarchelier C, Nowicki M, et al. (2014) Interindividual variability of lutein bioavailability in healthy men: characterization, genetic variants involved, and relation with fasting plasma lutein concentration. Am J Clin Nutr 100, 168-175.

57. Borel P, Desmarchelier C, Nowicki M, et al. (2015) Lycopene bioavailability is associated with a combination of genetic variants. Free Radic Biol Med 83, 238-244.

58. Institute of Medicine (2000) Dietary Reference Intakes: Applications in Dietary Assessment. Washington, DC: National Academies Press. https://doi.org/10.17226/9956 